\title{
Time to Explore Pharmacy Career Opportunities in the Private Sectors
}

\author{
Long Chiau Ming ${ }^{1,2, *}$, Allan Mathews ${ }^{1}$, Syed Atif Abbas ${ }^{1}$, Kah Seng Lee ${ }^{2}$ \\ 'Faculty of Pharmacy, Quest International University Perak, Ipoh, Perak, MALAYSIA. \\ ${ }^{2}$ Pharmacy, School of Medicine, University of Tasmania, Hobart, TAS, AUSTRALIA.
}

\section{ABSTRACT}

Pharmacy is a dynamic healthcare profession that allow role expansion into patient-care, manufacturing, management as well as entrepreneurship. The private sector provides a lucrative and promising platform for budding young pharmacists to build their career in healthcare. Apart from training opportunity and room for salary increment, the career pathway for a pharmacist in private practice is also diverse and bright. Fresh pharmacy graduates should explore this established career pathways. First, the growing number of private hospitals and role expansion of the pharmacist directly increases the demand of pharmacists in these private hospitals. Second, pharmacists are also a core team member in the pharmaceutical industry including the manufacturing sector not just because of the law requirement but also their expertise in formulation, production quality control, drug analysis, product registration and Good Manufacturing Practice (GMP). Third, the community pharmacy also provides a high potential platform to expand a young pharmacist's entrepreneurial skills, along with the role as a clinician and primary healthcare provider. Across Ministry of Health facilities as well as private healthcare, the pharmacist's roles are transitioning from product-focus to direct patient care. The shift to patient medicine management has long been successfully imple-
\end{abstract}

mented in developed countries, including Singapore and Australia, both at public and private facilities. The private sector, arising from the holistic and multiplicity nature of practice, is certainly as rewarding and job-satisfaction fulfilling as the public sector because the pharmacists interact in their multifaceted role as dispenser, clinician, retailer, entrepreneur and primary health advisor.

Key words: Work Satisfaction, Pharmaceutical Industry, Career Choices, Public Service.

\section{Correspondence}

Long Chiau Ming

Faculty of Pharmacy, Quest International University Perak, Ipoh, Level 2, Quest International University Perak, Plaza Teh Teng Seng, 227, Jalan Raja Permaisuri Bainun- 30250, Ipoh, Perak, MALAYSIA.

Phone: +605-249 0500

Email: ming.long@bath.edu

DOI: 10.5530/jyp.2019.11.67

\section{INTRODUCTION}

The recent Malaysia Government decision of not absorbing the contract pharmacists into permanent positions in the civil services has caused outcry of more than 3000 non-appointed contract pharmacists in the Malaysian Ministry of Health $(\mathrm{MoH})$. The whole chain of events can be traced back to September 2004 when compulsory public service for all newly registered pharmacists was first implemented, along with the enforcement of "Registration of Pharmacist Regulations 2004". ${ }^{1}$ The contract scheme was introduced to address the backlog of pharmacy graduates waiting to do their housemanship.

\section{The plight of short-term measure}

Under the new regulations, fresh pharmacy graduates ought to first undergo a one-year pre-registration housemanship before they can be fully registered with the Malaysian Pharmacy Board. After that, the fully registered pharmacist will have to serve for one further year of compulsory service. Prior to September 2013, the stipulated duration of compulsory service was three years. With the wisdom of hindsight, it was shortened to one year compulsory service in order to release more pharmacist workforce to the private practice. ${ }^{2}$

In order to reduce the prolonged waiting time for permanent government posting, $\mathrm{MoH}$ has resorted to offer the contract appointments for pharmacy graduates to undergo one-year housemanship training in $\mathrm{MOH}$ hospitals or health clinics. The first cohort of 512 graduates was appointed as contract pharmacists when it was first introduced in December 2016 and statistics indicates that up to 3500 contract pharmacists are now employed by $\mathrm{MoH}$. This short-term measure is also intended to allow those public service scholars or interested graduates to work in $\mathrm{MoH}$ for a maximum period of three years to fulfil the registration requirements of the Registration of Pharmacists Act 1951. ${ }^{1}$ Subsequently, the fully registered pharmacists have the option to work in the private sector in the pharmaceutical industry or community pharmacy or statutory bodies such as teaching hospitals (University Malaya Medical Centre, UKM Medical Centre etc), if they are not absorbed into permanent positions in the public service.

\section{Pharmacist Workforce Capacity in Malaysia}

Retrospectively, there were 416 Provisionally Registered Pharmacists (PRP, the new term used to replace the pupil or houseman pharmacist) in 2005 and the number of PRP in government service swelled to around 3500 by 2018 . This number is in proportion to the total fully registered pharmacists in $\mathrm{MoH}$. The total number of pharmacists in the public sector climbed steadily from 655 in 2001, to 1356 in 2005 and then further increased to 8376 in $2016^{3}$

Malaysia currently have a total of 20 recognised institutes of higher learning offering pharmacy degree. Out of these, six are public universities, with the latest addition of Universiti Sultan Zainal Abidin, Terengganu and re-instated University Malaya. Each year, close to a combined total of about 1200 pharmacy graduates are produced locally and overseas. The number of registered pharmacists in Malaysia has risen from 4999 in year 2005 to 14,599 in year 2016. A pharmacy graduate could 
practise as a fully registered pharmacist once completed and passed the one-year provisional training and qualifying examination governed by the Malaysian Pharmacy Board. Taking into account the growing Malaysian and pharmacist population, the ratio of pharmacist to population has reduced from 1:5290 in year 2005 to 1: 2185 in year $2016 .{ }^{3}$ It must be noted that Malaysia, including countries such as Denmark, Singapore and Netherland, has yet to achieve the 1:1000 ratio needed for optimum patient care. This notion was echoed in the local newspapers report "Malaysia needs more pharmacists to meet future demands- Health Ministry". In fact, an estimated additional 18000 new pharmacists are required to reach the WHO recommended pharmacist to population ratio, which may take more than ten years to achieve. ${ }^{4}$

\section{Scope of Pharmaceutical Services in Private Sectors}

In 2016, there were 187 private hospitals compared to 144 public hospitals in Malaysia. In addition, there were 73 private medium-size daycare centre and 10 private maternity hospitals operating in 2016. The current pharmacist workforce at $\mathrm{MoH}$ constituted 59\% of the total pharmacist population in Malaysia. On average, only two to four pharmacists are currently employed in each private hospital, compared to average number of 80-120 pharmacists in a district public hospital and 150-200 pharmacists in a state general hospital. In fact, Kuala Lumpur General Hospital currently has 260-270 pharmacists to cater to the multi-disciplinary services including oncology, paediatrics and geriatrics care. It is postulated that many more vacancies will be created in tandem with the expansion of clinical roles of pharmacists, specifically in the area of medicine management. Public hospitals have established about 12 medicine management clinics managed by the pharmacist. ${ }^{5}$

According to the Malaysia Health Minister, Datuk Seri Dr Dzulkefly Ahmad in his recent comments on the appointment of contract pharmacist into permanent establishment at $\mathrm{MoH}$, that apart from working in $\mathrm{MoH}$ facilities, there is also good demand in the private sectors for registered pharmacists holding the Type A Poisons Licence. Under the statutory requirement of Poisons Act 1952 and Regulations, at least one Type A licensed pharmacist is required in every private hospital, private healthcare centre, community pharmacy, pharmaceutical or veterinary wholesaler, manufacturing or even in the importing and exporting industries. The licensed pharmacist is a registered pharmacist who holds the required license to dispense his/her duties related to all types of controlled medications, which in legal terms are known as "scheduled poisons" and approved by the Malaysia Poisons Board. ${ }^{6}$

The emergence of medical tourism and private healthcare insurance have spurred the fast development of private hospitals. ${ }^{7,8}$ The growing number of private hospitals and role expansion of the pharmacist directly increases the demand of pharmacists in these private hospitals. But is the grass really greener on the private side? The standardization of PRP salary at about Malaysia currency MYR 2600 (equivalent to USD 620) at most private institutions is deemed less attractive compared to the PRP salary package as a grade junior (grade UF41) pharmacist in public service. Nevertheless, a big jump is expected upon the completion of PRP and being registered as a fully registered pharmacist in private sector. The expected salary could range from MYR 4500 to MYR 8000 (equivalent to USD 1080- USD 1910), inclusive of bonus, critical, housing and over-time allowances. In addition, pharmacists have the opportunity to be sent for accredited training on oncology services, medicine management, inventory control and hospital accreditation programme which also add value to their resume.

Apart from training opportunity and room for salary increment, the career pathway for a pharmacist in private practice is also diverse and bright. In addition to the conventional role of working in an outpatient pharmacy and inpatient pharmacy unit, the pharmacists can foray into clinical services in the wards, therapeutic drug monitoring, clinical oncology pharmacy, medication adherence clinic as well as parenteral nutrition services. ${ }^{9}$ A number of the chief operating officers and head of clinical services of some private hospitals in Malaysia are pharmacists, noting that there are opportunities to climb up the corporate ladder. Apparently, the glass ceiling effect for female pharmacists are blurred because many of the appointees are women..$^{9,10}$

Notably, there is a clear advantage to kickstart one's career in the undergraduate years by affiliating oneself at a university that provide solid training in healthcare management and associated services such as community pharmacy, geriatric care and in pharmaceutical operations. The early exposure to hospital environment during rotational pharmacy attachment throughout the four-year pharmacy programme would definitely gap the transition period towards pre-registration training.

Pharmacists are also a core team member in the pharmaceutical industry including the manufacturing sector not just because of the law requirement but also their expertise in formulation, production quality control, drug analysis, product registration and Good Manufacturing Practice (GMP). The scope of jobs that the pharmaceutical industry can offer to a pharmacist is wide and specific at the same time. For example, in a pharmaceutical manufacturing plant, as stipulated by the pharmacy law, it must employ a registered pharmacist for its licensure and operation. ${ }^{6}$ The industrial pharmacist will ensure the compliance of legal requirement of import and export of medicine, GMP etc. The manufacturing plant also requires a pharmacist to supervise production and manage the regulatory affairs. Meanwhile, a pharmacist who is a pharmaceuticals sales representative, has in depth knowledge of the medicines or products, promote and sell the product to the healthcare professionals as well as build relationships with them. A research and development pharmacist is entrusted to perform drug formulations, develop novel products and supervise the research team. At an advanced level, the research and development pharmacist will oversee the development of new medicines, cosmetic or devices. The job entails him or her to collaborate with the product engineer, physician and clinical research officer to monitor the timeline, budget and safety and efficacy of the product. The chemical or physical characteristics of a new product and manufactured samples also should be analysed by a laboratory analyst with a pharmacy background. The laboratory analyst who is a pharmacist has better competitive edge because he or she has sound knowledge of national compliance regulations and standards for drug analysis. To add to that, there is another interesting option that one can consider is working as a military pharmacist with the Royal Medical and Dental Corps of Malaysian Army, Ministry of Defence.

In conclusion, pharmacy is a dynamic healthcare profession that allow role expansion into patient-care, manufacturing, management as well as entrepreneurship. Across Ministry of Health facilities as well as private healthcare, the pharmacist's roles are transitioning from product-focus to direct patient care. The shift to patient medicine management has long been successfully implemented in developed countries, including Singapore and Australia, both at public and private facilities. The private sector provides a lucrative and promising platform for budding young pharmacists to build their career in healthcare. Fresh pharmacy graduates should explore this established career pathways especially during the time when the governmental postings are delayed. The private sector, arising from the holistic and multiplicity nature of practice, is certainly as rewarding and job-satisfaction fulfilling as the public sector because the pharmacists interact in their multifaceted role as dispenser, clinician, retailer and primary health advisor. 


\section{ACKNOWLEDGEMENT}

The authors are grateful to Quest International University Perak (QIU) for funding the publication fees.

\section{CONFLICT OF INTEREST}

The authors declare no conflict of interest.

\section{ABBREVIATIONS}

MoH: Ministry of Health; PRP: Provisionally Registered Pharmacists; WHO: World Health Organization; MYR: Malaysia Ringgit; USD: United States Dollar; GMP: good manufacturing practice.

\section{REFERENCES}

1. Ministry of Health Malaysia. Registration of Pharmacists Act 1951 and Regulations. Available from: https://www.pharmacy.gov.my/v2/en/documents/registration-pharmacists-act-1951-and-regulations.html.

2. Pharmaceutical Services Programme (Ministry of Health Malaysia). Guidelines on Liberalisation of PRP Training in Private Sector for Graduates of Pharmacy Degree Programme. Available from: https://www.pharmacy.gov.my/v2/en/ documents/guidelines-liberalisation-prp-training-private-sector-graduates-phar- macy-degree-programme.html.

3. Pharmacy Services Programme (Ministry of Health Malaysia). Annual Report Pharmacy Services Programme. Available online: https://www.pharmacy.gov. my/v2/en/documents/annual-report-pharmacy-services-programme.html.

4. International Pharmaceutical Federation (FIP). Pharmacy At A Glance, 20152017. Available from: https://www.fip.org/files/fip/publications/2017-09-Pharmacy_at_a_Glance-2015-2017.pdf.

5. Ministry of Health Malaysia. MOH Health Facts 2017. Available from: https:// mpaeds.my/moh-health-facts-2017/.

6. Pharmaceutical Services Programme (Ministry of Health Malaysia). Genera guideline on application for poisons licence, permit \& import authorisation for controlled substances. Available from: https://www.pharmacy.gov.my/v2/sites/ default/files/document-upload/general-guideline-application-poisons-licencepermit-and-import-export-authorisation-controlled.pdf.

7. Mutalib NSA, Soh YC, Wong TW, et al. Online narratives about medical tourism in Malaysia and Thailand: a qualitative content analysis. J Travel Tour Mark. 2016;1-12.

8. Abd MN, Ming L, Yee S, Wong P, Soh Y. Medical Tourism: Ethics, Risks and Benefits. Indian J Pharm Educ Res. 2016;50(2):261-70.

9. Aidit S, Shaharuddin S, Neoh CF, Ming LC. Evolvement of a warfarin medication therapy adherence clinic in Malaysia and its impact on international normalised ratio control over time. J Pharm Pract Res. 2015;45(4):431-2

10. Manan MM, Azmi Y, Lim Z, Neoh CF, Khan TM, Ming LC. Predictors of job satisfaction amongst pharmacists in Malaysian public hospitals and healthcare clinics. J Pharm Pract Res. 2015:45(4):404-11.

Article History: Submission Date : 26-05-2019; Revised Date : 15-06-2019; Acceptance Date : 01-07-2019.

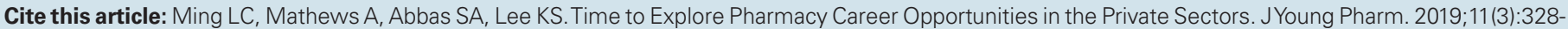
30 